\title{
Characterization of Quin-C1 for its anti-inflammatory property in a mouse model of bleomycin-induced lung injury
}

\author{
Min $\mathrm{HE}^{1}$, Ni CHENG ${ }^{2}$, Wei-wei GAO ${ }^{1}$, Meng ZHANG ${ }^{1}$, Yue-yun ZHANG ${ }^{1}$, Richard D YE ${ }^{2}$, Ming-wei WANG ${ }^{1, *}$ \\ ${ }^{1}$ The National Center for Drug Screening, the State Key Laboratory of Drug Research, Shanghai Institute of Materia Medica, Chinese \\ Academy of Sciences, Shanghai 201203, China; ${ }^{2}$ Department of Pharmacology, College of Medicine, University of Illinois, Chicago, IL \\ 60612, USA
}

\begin{abstract}
Aim: To study the in vivo effects of Quin-C1, a highly specific agonist for formyl peptide receptor 2 (FPR2/ALX), in a mouse model of bleomycin (BLM)-induced lung injury.

Methods: Male ICR mice were injected intratracheally with BLM (d 0), and intraperitoneally with Quin-C1 (0.2 mg/d) or vehicle between d 1 and d 28, during which pulmonary inflammation was monitored. A similar regimen was carried out between d 5 and d 28 to differentiate anti-inflammatory from anti-fibrotic effects. During the treatment, leukocyte numbers in bronchoalveolar lavage fluid (BALF)

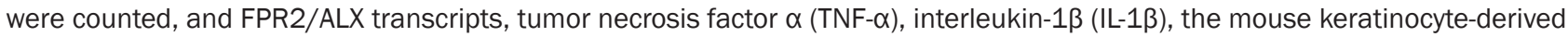
chemokine (KC), transforming growth factor $\beta 1$ (TGF- $\beta 1$ ) and C-X-C motif chemokine 10 (CXCL10) expression levels in the lung tissue were also measured. Both hydroxyproline content and histological changes were examined on d 28 to assess the severity of lung fibrosis.

Results: BLM caused a significant increase in expression levels of all the selected cytokines and chemokines, as well as a thickening of the alveolar wall. Treatment with Quin-C1 significantly reduced the neutrophil and lymphocyte counts in BALF, diminished expression of TNF- $\alpha$, IL-1 $1 \beta, K C$, and TGF- $\beta 1$, and decreased collagen deposition in lung tissue. The treatment also lowered the content of lung hydroxyproline. Quin-C1 did not ameliorate lung fibrosis when the treatment was started $5 \mathrm{~d}$ after the BLM challenge, suggesting that the protection may be attributed to its anti-inflammatory effects. Exposure to BLM or BLM plus Quin-C1 did not change the level of FPR2/ALX transcripts ( $\mathrm{mFpr1,} \mathrm{mFpr2}$, and Lxa4r) in the lung tissue.

Conclusion: The results demonstrate an anti-inflammatory role for Quin-C1 in bleomycin-induced lung injury, which may be further explored for therapeutic applications.
\end{abstract}

Keywords: Quin-C1; anti-inflammation; bleomycin; lung injury; formyl peptide receptor; cytokines

Acta Pharmacologica Sinica (2011) 32: 601-610; doi: 10.1038/aps.2011.4; published online 18 Apr 2011

\section{Introduction}

The G protein-coupled receptor (GPCR) formyl peptide receptor 2 (FPR2/ALX), also known as formyl peptide receptor-like 1 (FPRL1) and lipoxin A4 receptor (LXA4R), was initially identified as a structural homologue of human FPR $1^{[1]}$. FPR2/ALX prefers mitochondrial formyl peptides ${ }^{[2]}$ and is known for its promiscuous ligand recognition. More than 20 agonists have been identified for FPR2/ALX ${ }^{[1,3]}$, including many endogenous peptides and the eicosanoid LXA $4^{[4]}$. These ligands produce different effects on neutrophils, macrophages and epithelial cells that express FPR2/ALX. While most FPR2/

\footnotetext{
* To whom correspondence should be addressed.

E-mail wangmw@mail.shcnc.ac.cn

Received 2010-08-27 Accepted 2011-01-16
}

ALX agonists stimulate proinflammatory activities, others (including LXA4, annexin A1 and its N-terminal peptides) exhibit anti-inflammatory properties. For example, when used in vivo in a model of zymosan-induced peritonitis, LXA4 reduces neutrophil infiltration and pro-inflammatory cytokine expression ${ }^{[5]}$. LXA4 also binds to other receptors, including a receptor shared with cysteinyl leukotriene receptor type 1 $(\mathrm{CysLT1})^{[6]}$ and the aryl hydrocarbon receptor $(\mathrm{AhR})^{[7]}$. It was recently reported that mice lacking $m F p r 2$, which codes for mouse Fpr2, exhibited enhanced inflammatory responses in several models, such as IL-1 $\beta$-induced air pouch and zymosan-induced peritonitis ${ }^{[8]}$, indicating that the receptor mediates anti-inflammatory actions upon stimulation.

To identify small synthetic molecules as potential FPR2/ ALX-selective drug leads, we previously screened a com- 
pound library and identified Quin-C1 (4-butoxy- $\mathrm{N}-[2-(4-$ methoxy-phenyl)-4-oxo-1,4-dihydro-2H-quinazolin-3-yl]-benzamide) as an FPR2/ALX agonist ${ }^{[9]}$. In vitro pharmacological characterization showed that Quin-C1 stimulated neutrophil calcium mobilization and chemotaxis but had a very low efficacy in the induction of superoxide production ${ }^{[9]}$. In binding assays, Quin-C1 was found to occupy a site on FPR2/ALX that partially overlaps with the binding site for the potent FPR2/ ALX agonist WKYMVm ${ }^{[10]}$. These pharmacological properties indicate that Quin-C1 differs from most of the FPR2/ALX ligands identified to date and may selectively regulate biological functions in target cells.

In experimental animals, particularly rodents, bleomycin (BLM)-induced pulmonary fibrosis is a well-characterized model for investigating the pathogenesis of lung fibrosis ${ }^{[11-13]}$. BLM-induced pulmonary fibrosis results from an inflammatory response to lung injury, characterized by increased production of pro-inflammatory cytokines, including tumor necrosis factor $\alpha($ TNF- $\alpha$ ) and interleukin-1 $\beta$ (IL-1 $\beta)$, and chemokines such as macrophage inflammatory protein $1 a$ (MIP-1a), the mouse keratinocyte-derived chemokine (KC) and monocyte chemotactic protein 1 (MCP-1) ${ }^{[14]}$. Pathological changes associated with the progression to fibrosis include increased production of TGF- $\beta 1$, reactive oxygen species and C-X-C motif chemokine 10 (CXCL10) as well as decreased generation of adenosine triphosphate (ATP) and overproduction of mature collagen fibrils ${ }^{[15]}$. These changes eventually lead to thickening of the alveolar wall and reduction in blood oxygen exchange capacity.

In the present study, we investigated a potential anti-inflammatory function for Quin-C1 using a BLM-induced lung fibrosis model. Our data showed that mouse lung tissue expresses Quin-C1 receptors, and responds to Quin-C1 with reduced inflammatory cytokine expression and leukocyte infiltration leading to protection from BLM-induced lung injury. These results demonstrated an anti-inflammatory property for Quin$\mathrm{C} 1$ in vivo.

\section{Materials and methods}

\section{Animals and reagents}

Male ICR mice (9-10 weeks old, 25-30 g, Shanghai SLAC Laboratory Animals Co, Shanghai, China), widely used for fibrosis studies, were housed at $22.7 \pm 0.8^{\circ} \mathrm{C}$ with a $12 / 12$-h light/dark cycle. They were fed and watered ad libitum. All animal experiments were conducted in accordance with regulations and protocols approved by the Animal Care and Use Committee, Shanghai Institute of Materia Medica, Chinese Academy of Sciences. Quin-C1 was synthesized as described previously ${ }^{[9]}$.

\section{Calcium mobilization assay}

Mouse bone marrow polymorphonuclear (PMN) leukocytes (about 50000 cells/sample with about $75 \%$ neutrophils) and a rat basophil leukemia cell line (RBL-2H3) expressing mouse Fpr1 (mFpr1) or mouse Fpr2 (mFpr2) cDNA (about 40000 cells/sample) were placed in 96-well microtiter plates. The cells were incubated with FLIPR Calcium 5 reagent (Molecular Devices, Sunnyvale, CA, USA) at $37^{\circ} \mathrm{C}$ for $1 \mathrm{~h}$ and were excited at $485 \mathrm{~nm}$. $\mathrm{Ca}^{2+}$ fluorescence was detected at an emission wavelength of $525 \mathrm{~nm}$, using a FlexStation II (Molecular Devices) with an auto emission cutoff set at $515 \mathrm{~nm}$.

\section{BLM-induced lung injury and Quin-C1 treatment}

Lung injury was induced with BLM, as previously described, with minor modifications in dosage ${ }^{[16]}$. Briefly, bleomycin hydrochloride (Nippon Kayaku, Tokyo, Japan) was dissolved in $0.1 \mathrm{~mL}$ sterile saline and intratracheally injected into mouse lungs at a dose of $3 \mathrm{mg} / \mathrm{kg}$ body weight. Control animals received the same volume of saline. The day of BLM/saline administration was regarded as d 0. For intraperitoneal (ip) Quin-C1 treatment (daily from d 1 through d 28), mice were randomly assigned to one of three treatment groups with matching body weight: saline, BLM and BLM plus $0.2 \mathrm{mg}$ Quin-C1 (1\% DMSO, 19\% PEG400 in saline, $0.5 \mathrm{~mL}$, daily). A vehicle of equal volume was administered ip for comparison. Quin-C1 was also tested at $0.04 \mathrm{mg}$ and $1.0 \mathrm{mg}$ for doseresponse information. In an additional group, Quin-C1 was given on $\mathrm{d} 5$ at the fixed dose of $0.2 \mathrm{mg}$, and mice were sacrificed on d 9 for bronchoalveolar lavage fluid (BALF) analysis to measure leukocyte numbers. Lung tissue was also examined on d 9 for cytokine expression and on d 28 for signs of lung fibrosis, as detailed below.

\section{Detection of the transcripts of formyl peptide receptors in mouse lung}

Animals were sacrificed on d 0, 5, 7, 9, and 28 after BLM or saline administration and lungs were perfused with normal saline to remove blood cells. The lung tissue was then homogenized using TRIzol Reagent (Invitrogen, Carlsbad, CA, USA) for the preparation of total RNA. The total RNA $(2 \mu \mathrm{g})$ was reverse transcribed, and $1 \mu \mathrm{L}(1 / 20$ of the reverse transcriptase product) of the resulting cDNA was subjected to polymerase chain reaction (PCR) in a $25-\mu \mathrm{L}$ final reaction volume for analyzing levels of mouse Fpr1, Lxa4r and Fpr2 mRNA transcripts. $\beta$-actin was used as an internal control. The amplification conditions were as follows: initial step at $94^{\circ} \mathrm{C}$ for $5 \mathrm{~min}$, followed by 30 cycles at $95{ }^{\circ} \mathrm{C}$ for $30 \mathrm{~s}, 55^{\circ} \mathrm{C}$ for $1 \mathrm{~min}$ and $72{ }^{\circ} \mathrm{C}$ for 1 min. The primers and products for RT-PCR are presented in Table 1.

\section{BALF analysis}

On $\mathrm{d} 0,5,7$, and 9 following BLM or saline injection, the animals were sacrificed, and the lungs were lavaged twice with $0.8 \mathrm{~mL}$ PBS containing $5 \mathrm{mmol} / \mathrm{L}$ EDTA by cannulating the trachea. The BALF was centrifuged at 1500 revolutions per minute for $10 \mathrm{~min}$ at $4{ }^{\circ} \mathrm{C}$. To facilitate cell counting, the remaining red blood cells were eliminated with lysis buffer (Beyotime Institute of Biotechnology, Haimen, China). Total and differential cell counts (neutrophils, lymphocytes and macrophages) in the BALF were determined with the DiffQuick Stain Kit (IMEB Inc, San Marcos, CA, USA). 
Table 1. RT-PCR primers and products.

\begin{tabular}{|c|c|c|c|}
\hline $\begin{array}{l}\text { Mouse } \\
\text { gene }\end{array}$ & $\begin{array}{l}\text { Forward/ } \\
\text { reverse }\end{array}$ & $\begin{array}{c}\text { Primer sequence } \\
\left(5^{\prime} \text { to } 3^{\prime}\right)\end{array}$ & $\begin{array}{l}\text { Product } \\
\text { (bp) }\end{array}$ \\
\hline \multirow[t]{2}{*}{ Fpr1 } & Forward & GCACTGGACCGCTGTATTT & 519 \\
\hline & Reverse & CAAGGGGCTTGTGATTTTC & \\
\hline \multirow[t]{2}{*}{ Fpr2 } & Forward & GCCTGGCTAGGAAGGTGGTT & 352 \\
\hline & Reverse & CAAAAGGGCCACAAGCTGAA & \\
\hline \multirow[t]{2}{*}{ Lxa4r } & Forward & СCTGGGGCAACTCTGTTGAG & 381 \\
\hline & Reverse & AGTCCTGGCCCATGAAAACA & \\
\hline \multirow[t]{2}{*}{$\beta$-actin } & Forward & GGAAATTGTGCGTGACATCAAAG & 213 \\
\hline & Reverse & ATGCCACAGGATTCCATACCC & \\
\hline
\end{tabular}

Abbreviations: RT-PCR, reverse transcription-polymerase chain reaction; Fpr1, formyl peptide receptor 1; Lxa4r, lipoxin A4 receptor; Fpr2, formyl peptide receptor 2 .

\section{Measurement of cytokines in lung tissue}

Lung lobes were dissected from mice on d 0, 5, 7, and 9 and weighed. Samples were then homogenized on ice according to their respective weights ( $10 \%$ homogenate in saline). The homogenate supernatants were collected after centrifugation and assayed for levels of TNF- $\alpha$, IL-1 $\beta$, KC, TGF- $\beta 1$, and CXCL10 using specific ELISA kits (R\&D Systems Inc, Minneapolis, MN, USA). TGF- $\beta 1$ (latent and active) was measured after pre-activation with acidification to $\mathrm{pH} \mathrm{2-3} \mathrm{for} 60 \mathrm{~min}$, and corrected to $\mathrm{pH}$ 6.5-7.5 prior to ELISA assay.

\section{Measurement of hydroxyproline contents}

On d 28, all remaining animals were sacrificed, and the lung lobes were dissected and weighed. To measure the content of hydroxyproline in the lung, the tissue samples were homogenized and then hydrolyzed in $2 \mathrm{~mol} / \mathrm{L} \mathrm{NaOH}$ at $120^{\circ} \mathrm{C}$ for $20 \mathrm{~min}$. After the addition of chloramine T $(0.056 \mathrm{~mol} / \mathrm{L} ; \mathrm{eg}$, $1.27 \mathrm{~g}$ of chloramine $\mathrm{T}$ was dissolved in $20 \mathrm{~mL} \mathrm{50 \%} \mathrm{n-propa-}$ nol and brought to $100 \mathrm{~mL}$ with acetate-citrate buffer) and Ehrlich's reagent ( $1 \mathrm{~mol} / \mathrm{L}$; $e g, 15 \mathrm{~g}$ of p-dimethylaminobenzaldehyde was dissolved in n-propanol/perchloric acid (2:1 $v / v)$ and brought to $100 \mathrm{~mL}$ ), the absorbance of the samples was read at $557 \mathrm{~nm}$ on a microplate reader (Molecular Devices) ${ }^{[17]}$.

\section{Histopathology}

The right lung lobes removed from each mouse on d 28 were fixed in a $10 \%$ formalin solution and embedded in paraffin. Lung tissue sections (5- $\mu \mathrm{m}$ thickness) were cut and stained with Masson's trichrome (Sigma-Aldrich, St Louis, MO, USA) for histological examination under a light microscope (Olympus, Tokyo, Japan). Images were taken at $400 \times$ magnification. Alveolar wall thickness was determined by measuring the length of the lines drawn perpendicular to the narrowest segment of primary and secondary alveolar septa (60-80 lines per image at $100 \times$ magnification). The total number of septa counted for each group (3 mice) was 200-250, and the alveolar wall thickness was calculated using Image-Pro Plus 6.0 software (Media Cybernetics, Silver Spring, MD, USA) ${ }^{[18]}$.

\section{Statistical analysis}

Statistical analysis was performed using GraphPad Prism software (GraphPad, San Diego, CA, USA) by one-way or twoway analysis of variance (ANOVA), followed by Bonferroni post hoc analysis. Data are presented as mean \pm SEM. The criterion for significance was a probability of less than 0.05 .

\section{Results}

\section{Agonistic effect of Quin-C1 in mouse cells}

Quin-C1 was initially identified as an agonist for human FPR2/ALX ${ }^{[9]}$; however, its role in mice is yet to be established. We challenged mouse bone marrow-derived neutrophils with Quin-C1 in a calcium mobilization assay and compared the result with a WKYMVm-induced calcium response in the same cell population. As shown in Figure 1A, WKYMVm invoked dose-dependent calcium mobilization up to 100 $\mathrm{nmol} / \mathrm{L}$, and further increases in its concentration (up to 1 $\mu \mathrm{mol} / \mathrm{L}$ ) did not intensify the response. Quin-C1 at concentrations from $1 \mathrm{nmol} / \mathrm{L}$ to $10 \mu \mathrm{mol} / \mathrm{L}$ induced dose-dependent calcium mobilization in mouse neutrophils. When used at 10 $\mu \mathrm{mol} / \mathrm{L}$, Quin-C1 induced calcium mobilization levels similar to those produced by $10 \mathrm{nmol} / \mathrm{L}$ of WKYMVm (Figure 1B). These results are consistent with our previous finding, which demonstrated that Quin-C1 was approximately 1000-fold less potent as a ligand for FPR2/ALX than WKYMVm ${ }^{[9]}$.

To determine whether mFpr1 or mFpr2 is responsible for mediating the pharmacological functions of Quin-C1, we measured Quin-C1-induced calcium response in RBL cells expressing the receptors. Both mFpr1 and mFpr2 were able to mediate Quin-C1-induced calcium mobilization (Figures $1 \mathrm{C}$ and 1D). A better $\mathrm{EC}_{50}$ value $(35 \mathrm{nmol} / \mathrm{L})$ was obtained with cells expressing mFpr1 than cells expressing mFpr2 (166 nmol/L).

Effect of Quin-C1 on formyl peptide receptor expression in the lung tissue following BLM challenge

In mice, the formyl peptide receptor family contains at least eight genes, three of which are expressed in leukocytes ${ }^{[19]}$. In neutrophils, mFpr1 and mFpr2 are most abundant at the transcript level, whereas the mouse Lxa4r transcript (encoded by $m$ Fpr-rs1) is found at a lower level ${ }^{[20]}$. The same expression pattern was seen in lung tissue devoid of circulating neutrophils. Our data showed that the expression of these three formyl peptide receptors did not change in response to BLM (or BLM plus Quin-C1 exposure) at the mRNA level (Figure $1 \mathrm{E})$.

\section{Effect of Quin-C1 on BLM-induced leukocyte accumulation in the BALF}

To determine whether Quin-C1 affects the progression of BLM-induced chronic lung inflammation and fibrosis, mice were given intratracheal BLM (3 $\mathrm{mg} / \mathrm{kg})$ alone or together with Quin-C1 (0.2 mg, ip). As a negative control, normal saline was injected intratracheally in a separate group of mice. The outbred ICR strain used in this study is prone to fibrosis, such as Schistosoma mansoni-induced hepatic fibrosis ${ }^{[21]}$ and cyclophosphamide-induced lung fibrosis ${ }^{[22]}$. On the indicated 

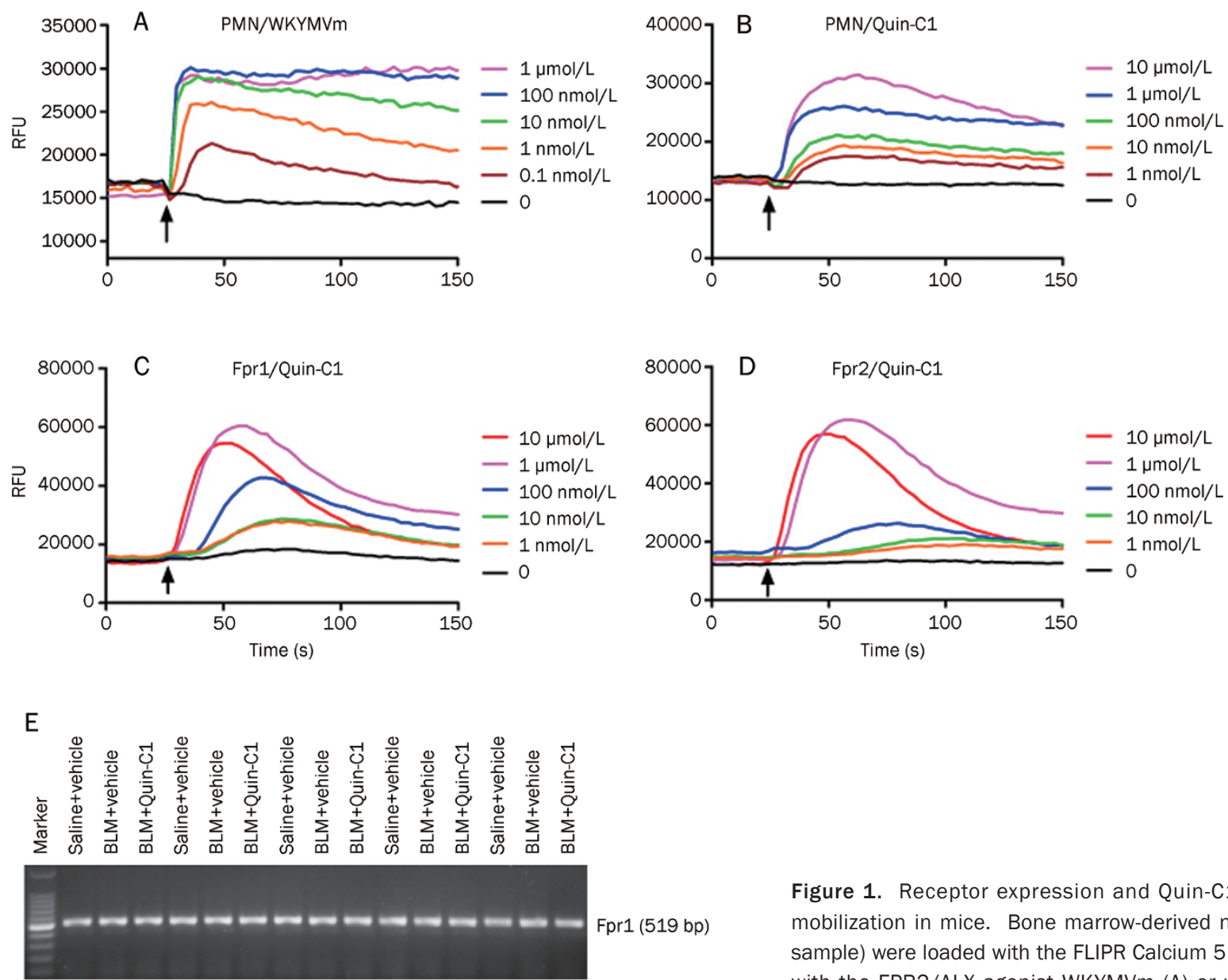

Fpr1 (519 bp)

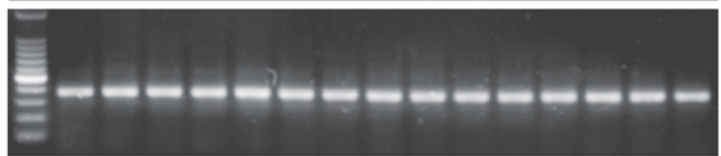

Fpr2 (352 bp)

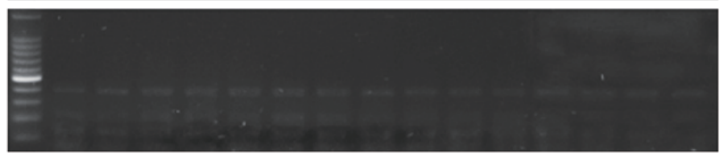

Lxa4r (381 bp)

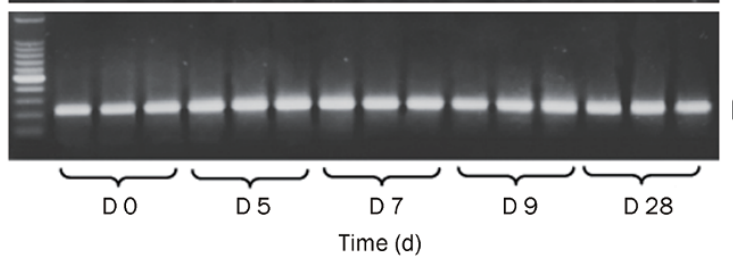

$\beta$-actin (213 bp)
Figure 1. Receptor expression and Quin-C1-induced calcium mobilization in mice. Bone marrow-derived neutrophils $\left(5 \times 10^{5}\right)$ sample) were loaded with the FLIPR Calcium 5 dye and stimulated with the FPR2/ALX agonist WKYMVm (A) or with Quin-C1 (B) at indicated concentrations. Real-time changes in intracellular calcium concentrations were determined using a FlexStation II and are shown in relative fluorescence units (RFU). One set of calcium tracings, representative of 3 repeating experiments, is shown. C and $D$, representative figures showing Quin-C1 induced calcium mobilization in transfected RBL cells expressing mouse Fpr1 (C) or mouse Fpr2 (D). The experiments were conducted as described in (A) and (B). E, effect of $0.2 \mathrm{mg}$ Quin-C1 on the expression of the transcripts for $3 \mathrm{Fpr}$ family members in mouse lung tissue on $\mathrm{d}$ $0,5,7,9$, and 28 after bleomycin (BLM) administration. Reverse transcription products were PCR-amplified for 30 cycles for detection of mouse Fpr1, Lxa4r and Fpr2 transcripts, respectively. The PCR products were analyzed on an agarose gel, and $\beta$-actin was used as an internal control. Marker: 100 bp DNA ladder. days after BLM or saline injection, the mice were sacrificed, and their lungs were lavaged as described above for total and differential cell counts. Mice receiving BLM had markedly higher total cell counts on $\mathrm{d} 7$ and $9(P<0.01)$; however, the increase was abolished in mice receiving both BLM and QuinC1 $(P<0.05$, Figure 2A). Differential leukocyte counts showed that the numbers of neutrophils and lymphocytes were increased in BALF from BLM-treated mice on d 5 and 9 after BLM induction $(P<0.01$, Figures $2 C$ and $2 D)$. Significantly fewer cells were found in BALF from mice receiving Quin-C1 for 7 or $9 \mathrm{~d}(P<0.01)$, indicating that Quin-C1 suppressed the infiltration of neutrophils and lymphocytes. The number of macrophages was also increased on $\mathrm{d} 7$ and 9 in the BLMtreated group $(P<0.01$, Figure $2 \mathrm{~B})$; however, Quin-C1 did not reverse the increase in macrophage number $(P>0.05)$.

Effect of Quin-C1 on the expression of cytokines and chemokines in the lung tissue of BLM-challenged mice

The expression levels of selected cytokines and chemokines were measured in lung tissue homogenates from mice sacrificed on d 5, 7, and 9 after BLM injection. As shown in Figure 3 , the expression levels of TNF- $\alpha$, IL-1 $\beta$, and KC were sig- 
A
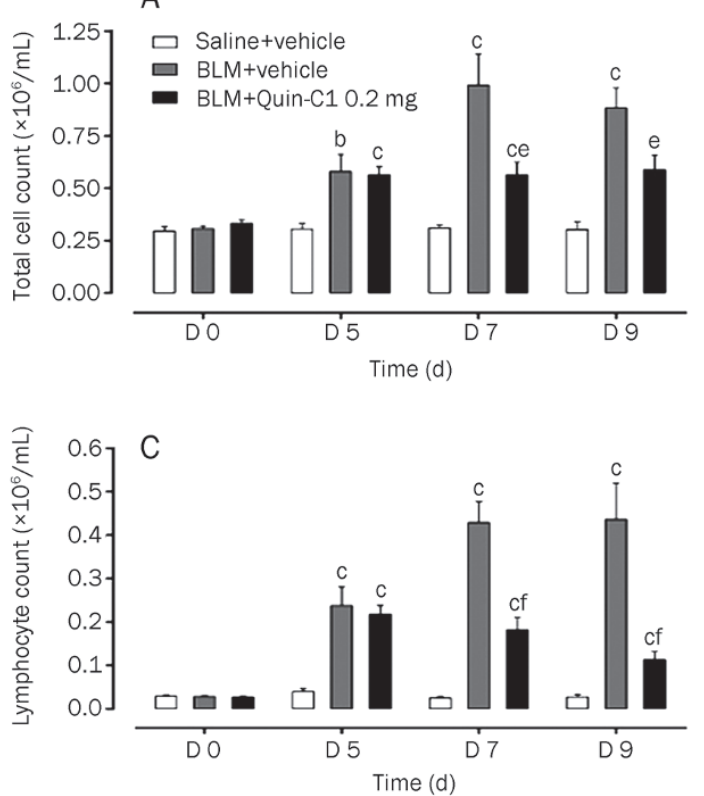

B
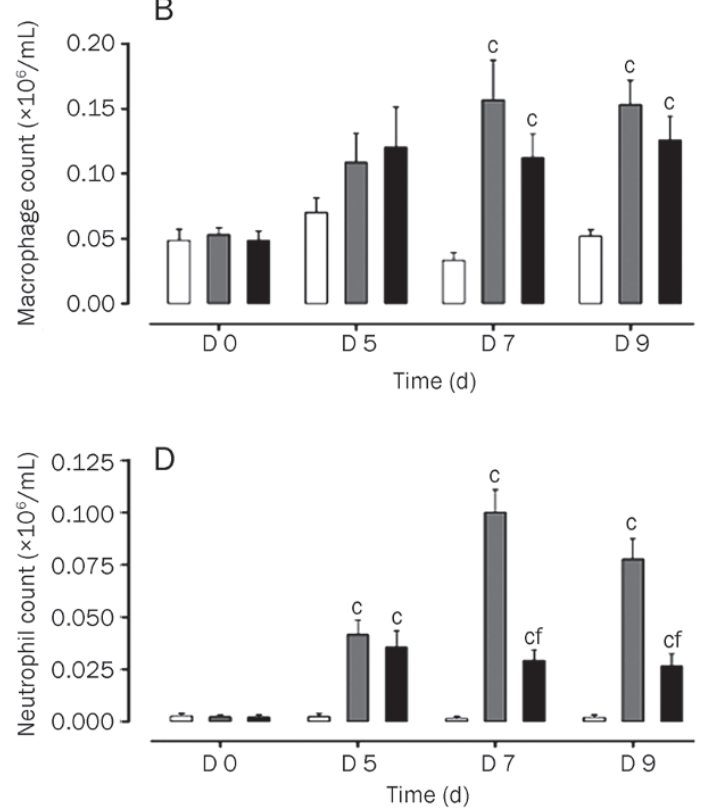

Figure 2. BLM induced changes in total and differential cell counts in the BALF and effects of Quin-C1. Mice were given intratracheal bleomycin (BLM) or saline injections ( $\mathrm{d}$ ), with or without daily Quin-C1 administration (0.2 mg or vehicle ip) starting on d 1. On d 0, 5, 7, and 9, mice from each group were sacrificed and the BALF was collected. Total cell count (A) was determined using a cell counter (Beckman Coulter, Fullerton CA, USA) and cell subset numbers were determined with Diff-quick staining (200 cells per animal were examined). Cell numbers for macrophages (B), lymphocytes (C) and neutrophils (D) in the BALF were calculated based on their respective percentage of the total cell count (A). Values are expressed as mean \pm SEM ( $n \geq 6$ per group). ${ }^{\mathrm{b}} P<0.05,{ }^{\mathrm{C}} P<0.01$ compared to saline control; ${ }^{\mathrm{e}} \mathrm{P}<0.05,{ }^{\mathrm{f}} \mathrm{P}<0.01$ compared to BLM control.
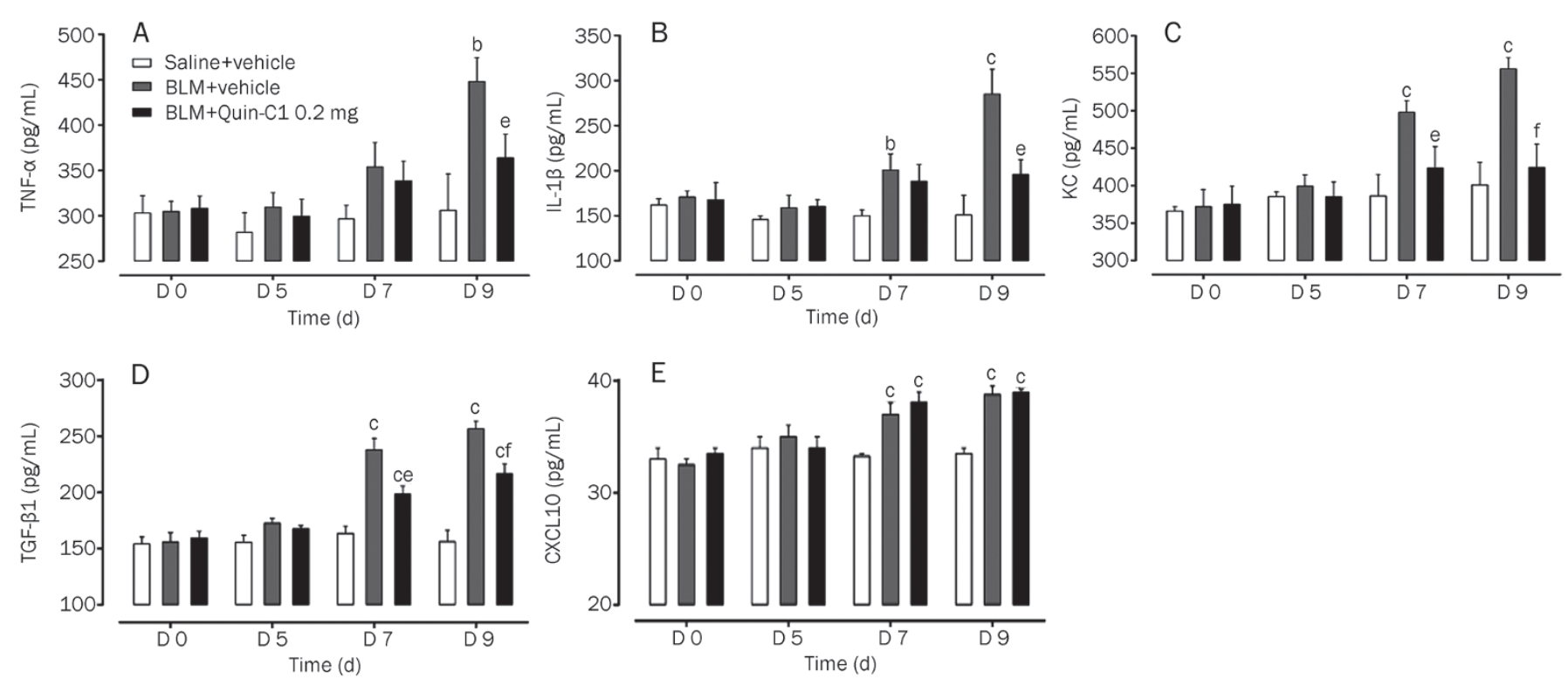

Figure 3. BLM induced expression of cytokines and chemokines in lung tissue and effects of Quin-C1. Bleomycin (BLM)-challenged mice were treated with Quin-C1 (0.2 mg) or vehicle as described above. On d 0,5, 7, and 9, the mice were sacrificed, and lung tissue homogenates were examined by ELISA for levels of TNF- $\alpha(A), I L-1 \beta(B), K C(C)$, TGF- $\beta 1(D)$, and CXCL10 (E). Values are expressed as mean \pm SEM $\left(n \geq 5\right.$ per group). ${ }^{b} P<0.05,{ }^{c} P<0.01$ compared to saline control; ${ }^{\mathrm{e}} \mathrm{P}<0.05,{ }^{\mathrm{f}} P<0.01$ compared to BLM control.

nificantly elevated on d 9 after BLM administration $(P<0.05$, $P<0.01$ and $P<0.01$, respectively). In addition, considerably higher levels of KC and IL- $1 \beta$ were detected on d $7 \quad(P<0.01$ and $P<0.05$, respectively). Administration of Quin-C1 reduced the expression level of these cytokines in lung tissue on $\mathrm{d}$ $9(P<0.01, P<0.05$, and $P<0.05$ for KC, TNF- $\alpha$, and IL- $1 \beta$, 


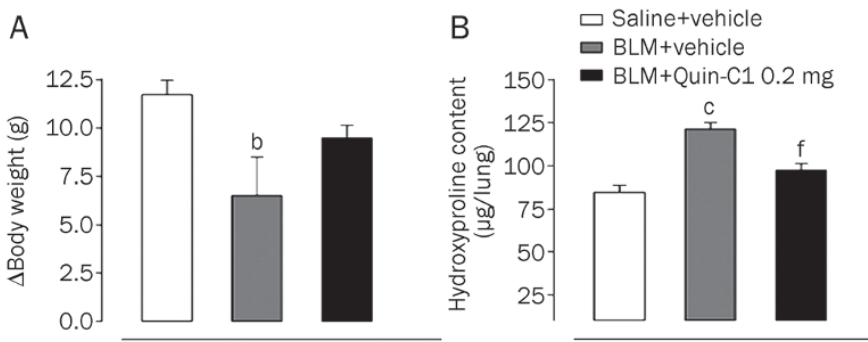

Figure 4. Effects of Quin-C1 on BLM induced body weight change and hydroxyproline content. The body weights of mice treated with saline, BLM and BLM plus Quin-C1 (0.2 mg) were monitored on d 0 and 28. The lung samples were homogenized and the contents of hydroxyproline measured on $\mathrm{d} 28$ as described in the methods. Values are expressed as mean \pm SEM ( $n \geq 10$ per group). ${ }^{b} P<0.05,{ }^{c} P<0.01$ compared to saline control; ${ }^{\mathrm{f}} P<0.01$ compared to BLM control.

respectively) and for $\mathrm{KC}$ only on d $7(P<0.05$, Figure 3$)$. These results suggest that Quin-C1 may partially offset the cytokinemediated effects of BLM.

TGF- $\beta 1$ plays a critical role in stimulating collagen synthesis by lung fibroblasts and contributes to the development of idiopathic pulmonary fibrosis ${ }^{[23,24]}$. The level of TGF- $\beta 1$ in lung tissue homogenates was determined by ELISA. Significantly higher levels of TGF- $\beta 1$ were found in mice receiving BLM on $\mathrm{d} 7$ and $9(P<0.01$, Figure 3D). In mice receiving Quin-C1, the BLM-induced TGF- $\beta 1$ production was partially inhibited $(P<0.05$ on $\mathrm{d} 7$ and $P<0.01$ on $\mathrm{d} 9$, compared to the levels of TGF- $\beta 1$ in mice treated with BLM alone, Figure 3D). The concentration of CXCL10 in lung tissue homogenates was markedly higher on $\mathrm{d} 7$ and 9 in mice treated with BLM than those that received saline $(P<0.01$, Figure 3E). Quin-C1 administration did not alter this finding at any time point assessed.

\section{Effect of Quin-C1 on BLM-induced weight loss and collagen deposition}

BLM induction causes long-term consequences that include collagen deposition into the lung tissue resulting in thickening of the alveolar wall, which directly contributes to the reduction in blood oxygen exchange ${ }^{[11]}$. BLM induction also leads to the eventual development of fibrosis, and these mice display weight loss. In the present study, mouse weight was monitored on $\mathrm{d} 0$ and 28. As shown in Figure 4A, a significant $(P<0.05)$ reduction in body weight was observed in mice receiving $B L M$ compared to those receiving saline. In addition, mice receiving BLM injection showed a $47 \%$ increase in the content of hydroxyproline, which reflects collagen deposition in the lung tissue (Figure 4B). These deleterious effects were partially inhibited in mice that received both BLM and Quin-C1 $(P<0.01$ for the lung hydroxyproline content, Figure $4 \mathrm{~B})$ although the weight loss was not completely prevented $(P>0.05$, Figure $4 \mathrm{~A})$.

Histological examination of the lung tissue was conducted to evaluate the severity of BLM-induced lung fibrosis and the morphological alterations following Quin- $\mathrm{C} 1$ intervention. On $\mathrm{d} 28$, the lung tissue from BLM-treated mice showed marked interstitial collagen deposition with a significant thickening of the alveolar septa (Figure 5B compared to 5A). In comparison, the mice that received Quin-C1 displayed a $75 \%$ reduction in BLM-induced thickening of alveolar walls (Figures 5C and $5 \mathrm{D})$. Collectively, these results indicate that Quin- $\mathrm{C} 1$ is capable of mitigating BLM-induced pulmonary fibrotic lesions.

\section{Dose-response characteristics of Quin-C1}

We next determined what Quin-C1 dosage was most efficacious in preventing BLM-induced lung injury. Our therapeutic protocol described above was repeated with Quin-C1 at doses of $0.04 \mathrm{mg}, 0.2 \mathrm{mg}$, and $1.0 \mathrm{mg}$. As shown in Figure 6, increasing the Quin-C1 dose from $0.04 \mathrm{mg}$ to $0.2 \mathrm{mg}$ enhanced protective effects by reducing leukocyte infiltration (primarily neutrophils, Figure 6A) and pro-inflammatory cytokine production in the BALF (Figure 6B). Interestingly, no protective effect was observed when the dose of Quin-C1 was further increased to $1.0 \mathrm{mg}$. However, no obvious detrimental effect on mouse body weight was observed with this dose $(1.0 \mathrm{mg})$ compared to the 0.04-mg and 0.2-mg dose groups (Figure 6C).

\section{Reduced lung fibrosis is secondary to the anti-inflammatory effects of Quin-C1}

Because BLM-induced lung fibrosis is preceded by an inflam-
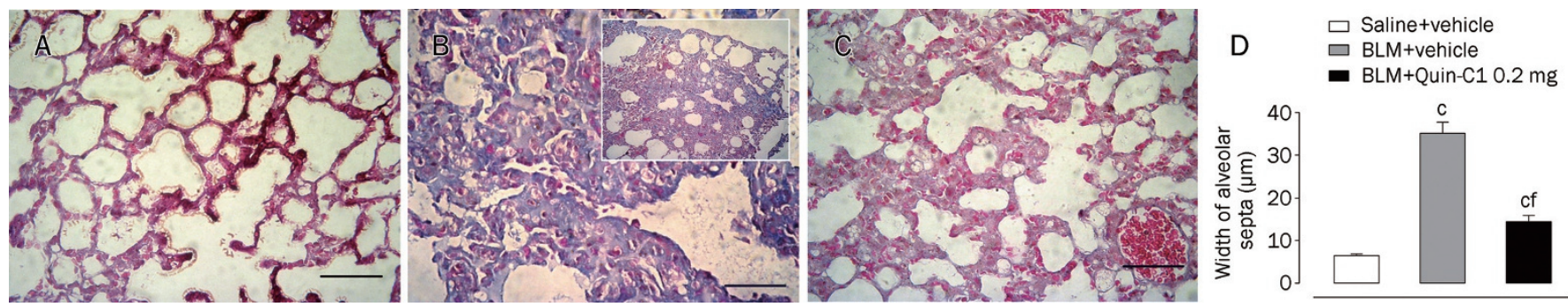

Figure 5. Histological analysis of BLM treated mouse lung tissue and effects of Quin-C1. Five-micrometer sections of lung tissue from mice receiving saline $(A), B L M(B)$ and BLM plus Quin-C1 $(0.2 \mathrm{mg})(C)$ were stained with Masson's trichrome for histological examination under a light microscope. (D) Alveolar wall thickness was determined using Image-Pro Plus 6.0 software and expressed as mean \pm SEM ( $n=3$ mice from each experimental group). Images were taken at $400 \times$ except in insert (B), which was taken at $100 \times$ to show collagen deposition in a larger area of lung tissue. Bar $=50 \mu \mathrm{m} ;{ }^{c} P<0.01$ compared to saline control; ${ }^{\mathrm{f}} P<0.01$ compared to BLM control. 

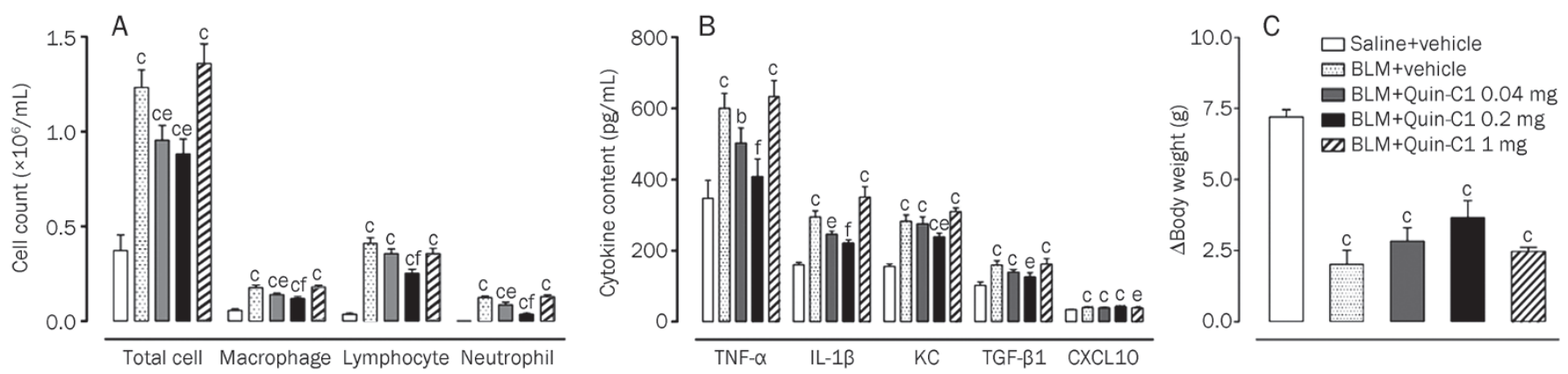

Figure 6. Effects of different doses of Quin-C1 on inflammatory cell counts in the BALF, expression of cytokines and chemokines in lung tissue and body weight change in BLM treated mice. Mice were challenged with BLM or saline on d 0, with or without daily Quin-C1 administration (0.04, 0.2, or 1 mg ip) starting on d 1. On d 9, mice were sacrificed to examine the total and differential cell counts in the BALF (A), TNF- $\alpha$, IL-1 $1 \beta$, KC, TGF- $\beta 1$, and CXCL10 levels in lung homogenates (B) and body weight changes $(C)$. Values are expressed as mean \pm SEM ( $n \geq 8$ per group). ${ }^{b} P<0.05$, ${ }^{\mathrm{C}} P<0.01$ compared to saline control; ${ }^{\mathrm{e}} \mathrm{P}<0.05,{ }^{\mathrm{f}} \mathrm{P}<0.01$ compared to BLM control.

matory response in the lung, we sought to determine whether the protective effect of Quin-C1 results from its anti-inflammatory property or from an additional anti-fibrotic function. For this experiment, Quin-C1 $(0.2 \mathrm{mg})$ was given from d 5 through d 9 or 28 after intratracheal administration of BLM or saline. Groups of mice were sacrificed on d 9 for leukocyte counts and cytokine measurements in the BALF and on d 28 to examine alveolar septa thickness and hydroxyproline content. Our results (supplementary Figure S1) show that the administration of $0.2 \mathrm{mg}$ Quin-C1 from d 5 through d 9 or 28 produced neither a protective effect against BLM-induced lung inflammation and fibrosis nor any detrimental impact on uninjured lungs from mice treated with saline.

\section{Discussion}

Results from the present study demonstrate an anti-inflammatory property for Quin-C1. Here, we describe this function in vivo in a mouse model of lung fibrosis, which is induced by an inflammatory response to BLM injury and is characterized by increased leukocyte infiltration, proinflammatory cytokine expression and deposition of collagen in alveolar septa. Published BLM-induced fibrosis studies showed a significant increase in TNF- $\alpha$, IL-1 $\beta$ and TGF- $\beta 1$ lung cytokine levels ${ }^{[14]}$. Inhibition of pro-inflammatory cytokine expression, such as by blocking nuclear factor $\mathrm{\kappa B}$ (NF- $\mathrm{kB}$ ) activation, reduces BLM-induced fibrosis ${ }^{[25,26]}$. Suppression of other proinflammatory transcriptional pathways, including the p38 mitogen-activated protein kinase (p38 MAPK) pathway, also decreases lung fibrosis in response to $\mathrm{BLM}^{[27]}$. Therefore, the anti-inflammatory effects of Quin-C1 are likely responsible for the reduced pathological changes in lungs exposed to BLM. To determine further whether Quin- $\mathrm{C} 1$ has anti-fibrotic properties, we administered it on d 5 through d 28 following BLM challenge. Our data show that delayed administration of Quin-C1 abrogated its protective effect, indicating that Quin$\mathrm{C} 1$ is incapable of reversing the fibrotic phenotype caused by the initial inflammatory response to BLM. These findings suggest that the protective effect of Quin-C1 results from its antiinflammatory properties and that the observed anti-fibrotic effect is secondary.

In addition to an increase in pro-inflammatory cytokine expression, BLM-induced lung fibrosis is preceded by increased local synthesis of chemokines, including MCP-1, MIP-2 and $\mathrm{KC}^{[28]}$. In this study, increases in $\mathrm{KC}$ expression are consistent with increased neutrophil and lymphocyte infiltration in the lung tissue. Local accumulation of leukocytes, particularly neutrophils, is a contributing factor to lung fibrosis, which develops in mice affected by BLM. Indeed, previous investigations indicate that decreased pulmonary fibrosis is associated with reduced accumulation of leukocytes, including neutrophils and lymphocytes ${ }^{[29]}$. However, although neutrophil infiltration and neutrophil-endothelial cell interactions are considered important to the development of lung fibrosis (as shown in studies using mice lacking both L-selectin and intercellular adhesion molecular-1 (ICAM-1) ${ }^{[29]}$ ), the role of T lymphocytes in BLM-induced lung fibrosis remains controversial. There is evidence in the literature to suggest that BLMinduced lung fibrosis does not require $\mathrm{T}$ cells ${ }^{[30]}$. However, another published study demonstrated that CD28 deficiency abolished BLM-induced lung fibrosis, whereas adoptive transfer of wild type $\mathrm{T}$ cells restored this capability ${ }^{[31]}$. Thus, it is possible that one of the anti-inflammatory functions of Quin$\mathrm{C} 1$ mediates the suppression of leukocyte infiltration, thereby reducing local inflammation and neutrophil-mediated tissue injury.

The attenuation of BLM-induced lung fibrosis has been observed in several studies. For example, the suppression of interferon- $\gamma($ IFN- $\gamma)$ signaling abrogates BLM-induced lung fibrosis $^{[32]}$ and neutralizing interleukin-13 (IL-13) produces similar effects, implying that IL-13 plays an important role in the progression of chronic lung inflammation ${ }^{[33]}$. We have shown that BLM stimulates TGF- $\beta 1$ expression in mice, and Quin-C1 partially reverses this phenomenon. One established function of TGF- $\beta 1$ is to stimulate collagen synthesis by fibroblasts, which directly contributes to tissue fibrosis ${ }^{[23,24]}$. Fibroblasts also respond to TGF- $\beta 1$ by stimulating $\mathrm{c}-\mathrm{Abl}$ kinase activity. The inhibition of c-Abl by the drug imatinib prevents TGF- $\beta 1$-induced extracellular membrane (ECM) gene 
expression, morphologic transformation, and cell proliferation, and reduces BLM-induced lung fibrosis ${ }^{[34]}$. Quin-C1 may target these pathways to induce its anti-inflammatory effects; however, the exact target(s) and underlying mechanisms of action remain to be elucidated. The chemokine CXCL10, which is highly expressed in BLM-induced pulmonary fibrosis, has been shown to attenuate the development of fibrosis via inhibition of fibroblast recruitment or angiogenesis ${ }^{[35]}$. Up-regulating CXCL10 is associated with a reduction in fibroblast accumulation in the lung ${ }^{[36]}$. Our findings show a significant increase in CXCL10 levels on d 7 and 9 after BLM challenge. The observation that Quin- $\mathrm{C} 1$ has no direct effect on CXCL10 expression implies that it was unable to modulate the CXCL10 pathway in response to BLM exposure.

Quin-C1 is identified as an FPR2/ALX-selective agonist ${ }^{[9]}$. FPR2/ALX binds to LXA4, and this receptor contributes to the potent anti-inflammatory properties of LXA4 and annexin A1. It is believed that these functions are mediated through the suppression of neutrophil accumulation, inhibition of NF-KB activation, and enhancement of pro-resolving functions such as macrophage-mediated phagocytosis of apoptotic neutrophils ${ }^{[5,37]}$. Our results show an abundant expression of both mFpr1 and mFpr2 transcripts in mouse lung tissue, and the latter is reported to be a receptor for LXA4 ${ }^{[38]}$. Moreover, Quin-C1 induces calcium mobilization in mouse neutrophils, which express mFpr1 and $\mathrm{mFpr} 2$ transcripts ${ }^{[20]}$. Interestingly, our data indicate that both $\mathrm{mFpr} 1$ and $\mathrm{mFpr} 2$ are able to mediate Quin-C1-induced calcium mobilization and, based on the $\mathrm{EC}_{50}$ value, $\mathrm{mFpr} 1$ is more potent. Because $\mathrm{mFpr} 1$ shares high sequence homology and structural features with human FPR2/ALX, it is not surprising that this receptor also interacts with Quin-C1. Therefore, either one or both receptors may be responsible for the actions of Quin-C1 observed in this study. Recently, Dufton and colleagues reported that genetic deletion of $\mathrm{mFpr} 2$ gene led to an increase in inflammation in several mouse models, providing genetic evidence that $\mathrm{mFpr} 2$ is the equivalent of human FPR2/ALX, which mediates the antiinflammatory functions of selected ligands ${ }^{[8]}$. However, Chen and colleagues ${ }^{[39]}$ demonstrated a reduced allergic inflammation in the absence of this receptor using $\mathrm{mFpr} 2$ gene knockout mice. It is also notable that mFpr1 was not previously known as a functional homologue of FPR2/ALX in terms of its antiinflammatory properties. Therefore, follow-up work is necessary to better characterize these two receptors using genetically altered animals.

It is intriguing that a $G$ protein-coupled chemoattractant receptor, such as FPR2/ALX, mediates both neutrophilactivating and anti-inflammatory effects in vivo. Currently, there is not a clearly identified mechanism to explain these observations, but emerging evidence suggests several possibilities. First, all identified FPR2/ALX ligands that possess anti-inflammatory properties are agonists that elicit selected functions through the receptor. For example, LXA4 stimulates guanosine triphosphatase (GTPase) through FPR2/ALX ${ }^{[4]}$. In addition, annexin $\mathrm{A} 1$ and its $\mathrm{N}$-terminal derived peptides activate the mitogen-activated protein kinase/extracellular signal-regulated kinase (MAPK/ERK) pathways ${ }^{[8,40]}$. However, these ligands are weak agonists compared to WKYMVm and serum amyloid A for stimulating other neutrophil actions. It is likely that the receptor is only partially activated when exposed to the ligands with anti-inflammatory properties. This introduces the second possibility, which relates to a dose effect. In our experiments, we observed protective effects of Quin-C1 in a narrow range of doses (between 0.04 to $0.2 \mathrm{mg}$ ). Further increasing the Quin- $\mathrm{C} 1$ dose to $1 \mathrm{mg}$ completely abrogated the anti-inflammatory effect. Although the underlying mechanism remains unclear, it is of note that LXA4 produces anti-inflammatory effects at doses in the nanomolar range ${ }^{[5]}$, whereas other properties of the ligand appear at higher concentrations ${ }^{[41]}$. Thus, it is necessary to further determine the dose-response characteristics of these ligands at the level of receptors and receptor-mediated signaling pathways. Finally, the FPR2/ALX-mediated agonistic activities of selected ligands appear to be indispensable for inducing anti-inflammatory proteins such as suppressor of cytokine signaling 2 (SOCS-2) as well as enhancing the proresolving functions of macrophages ${ }^{[42,43]}$. Consistent with these findings, FPR2/ALX has been shown to mediate different functions of LXA4 in neutrophils and macrophages ${ }^{[4]}$. For example, LXA4 inhibits neutrophil infiltration and stimulates macrophage-mediated phagocytosis of apoptotic neutrophils. Complementary studies have also shown that small molecules serving as FPR2/ALX agonists possess anti-inflammatory functions in vivo ${ }^{[45]}$. The protective effect of Quin-C1 may also arise from its ability to inhibit TGF- $\beta 1$ expression in BLMtreated lungs. In line with these observations, it is likely that the recently reported anti-fibrotic property of LXA4 may be due to its anti-inflammatory functions ${ }^{[46]}$. Although Quin-C1 has been pharmacologically characterized in greatest detail for its agonistic function at human FPR2/ALX $X^{[9]}$, the identification of two mouse FPR family members as potential targets for this ligand suggests that the anti-inflammatory properties of these receptors are shared between species and can be useful for more in-depth analysis in mice. Collectively, the available experimental data suggest the feasibility for using FPR2/ALX agonists to treat certain inflammatory disorders. Additional investigations are required to determine the signaling mechanisms that underlie the observed anti-inflammatory functions of these agents.

\section{Acknowledgements}

We are indebted to Xiang MENG, Xiao-yan WU, and Haoran SU for technical assistance. This work was supported in part by grants from the Ministry of Science and Technology of China (2009ZX09302-001), Shanghai Municipality government (08430703200 and 09DZ2291200) and the National Institutes of Health, USA (AI033503).

\section{Author contribution}

Richard D YE and Ming-Wei WANG designed the research; Min HE, Ni CHENG, Wei-wei GAO, Meng ZHANG, and Yue-yun ZHANG performed the experiments; Min HE, Ni 
CHENG, Richard D YE, and Ming-Wei WANG analyzed the data; and Richard D YE and Ming-Wei WANG wrote the paper.

\section{Supplementary information}

Supplementary figure is available at Acta Pharmacologica Sinica website of NPG.

\section{References}

1 Migeotte I, Communi D, Parmentier M. Formyl peptide receptors: a promiscuous subfamily of $\mathrm{G}$ protein-coupled receptors controlling immune responses. Cytokine Growth Factor Rev 2006; 17: 501-19.

2 Rabiet MJ, Huet E, Boulay F. Human mitochondria-derived $\mathrm{N}$-formylated peptides are novel agonists equally active on FPR and FPRL1, while Listeria monocytogenes-derived peptides preferentially activate FPR. Eur J Immunol 2005; 35: 2486-95.

3 Ye RD, Boulay F, Wang JM, Dahlgren C, Gerard C, Parmentier M, et al. International Union of Basic and Clinical Pharmacology. LXXIII. Nomenclature for the formyl peptide receptor (FPR) family. Pharmacol Rev 2009; 61: 119-61.

4 Fiore S, Maddox JF, Perez HD, Serhan CN. Identification of a human cDNA encoding a functional high affinity lipoxin A4 receptor. J Exp Med 1994; 180: 253-60.

5 Serhan CN. Lipoxins and aspirin-triggered 15-epi-lipoxins are the first lipid mediators of endogenous anti-inflammation and resolution. Prostaglandins Leukot Essent Fatty Acids 2005; 73: 141-62.

6 Chiang N, Serhan CN, Dahlen SE, Drazen JM, Hay DW, Rovati GE, et al. The lipoxin receptor ALX: potent ligand-specific and stereoselective actions in vivo. Pharmacol Rev 2006; 58: 463-87.

7 Schaldach CM, Riby J, Bjeldanes LF. Lipoxin A4: a new class of ligand for the Ah receptor. Biochemistry 1999; 38: 7594-600.

8 Dufton N, Hannon R, Brancaleone V, Dalli J, Patel HB, Gray M, et al. Anti-inflammatory role of the murine formyl-peptide receptor 2: ligand-specific effects on leukocyte responses and experimental inflammation. J Immunol 2010; 184: 2611-9.

9 Nanamori M, Cheng X, Mei J, Sang H, Xuan Y, Zhou C, et al. A novel nonpeptide ligand for formyl peptide receptor-like 1 . Mol Pharmacol 2004; 66: 1213-22.

10 Le Y, Gong W, Li B, Dunlop NM, Shen W, Su SB, et al. Utilization of two seven-transmembrane, $G$ protein-coupled receptors, formyl peptide receptor-like 1 and formyl peptide receptor, by the synthetic hexapeptide WKYMVm for human phagocyte activation. J Immunol 1999; 163: 6777-84.

11 Adamson IY, Bowden DH. The pathogenesis of bloemycin-induced pulmonary fibrosis in mice. Am J Pathol 1974; 77: 185-97.

12 Chua F, Gauldie J, Laurent GJ. Pulmonary fibrosis: searching for model answers. Am J Respir Cell Mol Biol 2005; 33: 9-13.

13 Moore BB, Hogaboam CM. Murine models of pulmonary fibrosis. Am J Physiol Lung Cell Mol Physiol 2008; 294: L152-60.

14 Phan SH, Kunkel SL. Lung cytokine production in bleomycin-induced pulmonary fibrosis. Exp Lung Res 1992; 18: 29-43.

15 Keane MP. The role of chemokines and cytokines in lung fibrosis. Eur Respir Rev 2008; 17: 151-6.

16 Waseda Y, Yasui M, Nishizawa Y, Inuzuka K, Takato H, Ichikawa Y, et al. Angiotensin II type 2 receptor antagonist reduces bleomycininduced pulmonary fibrosis in mice. Respir Res 2008; 9: 43.

17 Reddy GK, Enwemeka CS. A simplified method for the analysis of hydroxyproline in biological tissues. Clin Biochem 1996; 29: 225-9.

18 Pua ZJ, Stonestreet BS, Cullen A, Shahsafaei A, Sadowska GB, Sunday $\mathrm{ME}$. Histochemical analyses of altered fetal lung development follow- ing single vs multiple courses of antenatal steroids. J Histochem Cytochem 2005; 53: 1469-79.

19 Wang ZG, Ye RD. Characterization of two new members of the formyl peptide receptor gene family from 12956 mice. Gene 2002; 299: 57-63.

20 Southgate EL, He RL, Gao JL, Murphy PM, Nanamori M, Ye RD. Identification of formyl peptides from Listeria monocytogenes and Staphylococcus aureus as potent chemoattractants for mouse neutrophils. J Immunol 2008; 181: 1429-37.

21 Cheever AW, Dunn MA, Dean DA, Duvall RH. Differences in hepatic fibrosis in ICR, C3H, and C57BL/ 6 mice infected with Schistosoma mansoni. Am J Trop Med Hyg 1983; 32: 1364-9.

22 Kanekal S, Fraiser L, Kehrer JP. Pharmacokinetics, metabolic activation, and lung toxicity of cyclophosphamide in C57/B16 and ICR mice. Toxicol Appl Pharmacol 1992; 114: 1-8.

23 Branton MH, Kopp JB. TGF-beta and fibrosis. Microbes Infect 1999; 1: 1349-65.

24 Sheppard D. Transforming growth factor beta: a central modulator of pulmonary and airway inflammation and fibrosis. Proc Am Thorac Soc 2006; 3: 413-7.

25 Gurujeyalakshmi G, Wang Y, Giri SN. Taurine and niacin block lung injury and fibrosis by down-regulating bleomycin-induced activation of transcription nuclear factor-kappaB in mice. J Pharmacol Exp Ther 2000; 293: 82-90.

26 Inayama M, Nishioka Y, Azuma M, Muto S, Aono Y, Makino H, et al. A novel IkappaB kinase-beta inhibitor ameliorates bleomycin-induced pulmonary fibrosis in mice. Am J Respir Crit Care Med 2006; 173: 1016-22.

27 Matsuoka H, Arai T, Mori M, Goya S, Kida H, Morishita H, et al. A p38 MAPK inhibitor, FR-167653, ameliorates murine bleomycin-induced pulmonary fibrosis. Am J Physiol Lung Cell Mol Physiol 2002; 283: L103-12.

28 Yara S, Kawakami K, Kudeken N, Tohyama M, Teruya K, Chinen $\mathrm{T}$, et al. FTS reduces bleomycin-induced cytokine and chemokine production and inhibits pulmonary fibrosis in mice. Clin Exp Immunol 2001; 124: 77-85.

29 Hamaguchi Y, Nishizawa Y, Yasui M, Hasegawa M, Kaburagi Y, Komura $\mathrm{K}$, et al. Intercellular adhesion molecule-1 and L-selectin regulate bleomycin-induced lung fibrosis. Am J Pathol 2002; 161: 1607-18.

30 Helene M, Lake-Bullock V, Zhu J, Hao H, Cohen DA, Kaplan AM. T cell independence of bleomycin-induced pulmonary fibrosis. J Leukoc Biol 1999; 65: 187-95.

31 Okazaki T, Nakao A, Nakano H, Takahashi F, Takahashi K, Shimozato O, et al. Impairment of bleomycin-induced lung fibrosis in CD28-deficient mice. J Immunol 2001; 167: 1977-81.

32 Chen ES, Greenlee BM, Wills-Karp M, Moller DR. Attenuation of lung inflammation and fibrosis in interferon-gamma-deficient mice after intratracheal bleomycin. Am J Respir Cell Mol Biol 2001; 24: 545-55.

33 Belperio JA, Dy M, Burdick MD, Xue YY, Li K, Elias JA, et al. Interaction of IL-13 and C10 in the pathogenesis of bleomycin-induced pulmonary fibrosis. Am J Respir Cell Mol Biol 2002; 27: 419-27.

34 Daniels CE, Wilkes MC, Edens M, Kottom TJ, Murphy SJ, Limper AH, et al. Imatinib mesylate inhibits the profibrogenic activity of TGF-beta and prevents bleomycin-mediated lung fibrosis. J Clin Invest 2004; 114: 1308-16.

35 Strieter RM, Gomperts BN, Keane MP. The role of CXC chemokines in pulmonary fibrosis. J Clin Invest 2007; 117: 549-56.

36 Tager AM, Kradin RL, LaCamera P, Bercury SD, Campanella GS, Leary $\mathrm{CP}$, et al. Inhibition of pulmonary fibrosis by the chemokine IP-10/ CXCL10. Am J Respir Cell Mol Biol 2004; 31: 395-404.

37 O'Meara SJ, Rodgers K, Godson C. Lipoxins: update and impact of 
endogenous pro-resolution lipid mediators. Rev Physiol Biochem Pharmacol 2008; 160: 47-70.

38 Vaughn MW, Proske RJ, Haviland DL. Identification, cloning, and functional characterization of a murine lipoxin A4 receptor homologue gene. J Immunol 2002; 169: 3363-9.

39 Chen K, Le Y, Liu Y, Gong W, Ying G, Huang J, et al. A critical role for the $G$ protein-coupled receptor mFPR2 in airway inflammation and immune responses. J Immunol 2010; 184: 3331-5.

40 Walther A, Riehemann K, Gerke V. A novel ligand of the formyl peptide receptor: annexin I regulates neutrophil extravasation by interacting with the FPR. Mol Cell 2000; 5: 831-40.

41 Bae YS, Park JC, He R, Ye RD, Kwak JY, Suh PG, et al. Differential signaling of formyl peptide receptor-like 1 by Trp-Lys-Tyr-Met-Val-MetCONH2 or lipoxin A4 in human neutrophils. Mol Pharmacol 2003; 64: 721-30.

42 Machado FS, Johndrow JE, Esper L, Dias A, Bafica A, Serhan CN, et al. Anti-inflammatory actions of lipoxin A4 and aspirin-triggered lipoxin are SOCS-2 dependent. Nat Med 2006; 12: 330-4.

43 Godson C, Mitchell S, Harvey K, Petasis NA, Hogg N, Brady HR. Cutting edge: lipoxins rapidly stimulate nonphlogistic phagocytosis of apoptotic neutrophils by monocyte-derived macrophages. J Immunol 2000; 164: 1663-7.

44 Romano M, Maddox JF, Serhan CN. Activation of human monocytes and the acute monocytic leukemia cell line (THP-1) by lipoxins involves unique signaling pathways for lipoxin A4 versus lipoxin B4: evidence for differential $\mathrm{Ca}^{2+}$ mobilization. J Immunol 1996; 157: 2149-54.

45 Burli RW, Xu H, Zou X, Muller K, Golden J, Frohn M, et al. Potent hFPRL1 (ALXR) agonists as potential anti-inflammatory agents. Bioorg Med Chem Lett 2006; 16: 3713-8.

46 Martins V, Valenca SS, Farias-Filho FA, Molinaro R, Simoes RL, Ferreira TP, et al. ATLa, an aspirin-triggered lipoxin A4 synthetic analog, prevents the inflammatory and fibrotic effects of bleomycininduced pulmonary fibrosis. J Immunol 2009; 182: 5374-81. 